\title{
Middle School Student Analogy Process in Solving Algebra Problems based on Example Questions in terms of Students Divergent Thinking Ability
}

\author{
Dwi Priyo Utomo, University of Muhammadiyah Malang, dwipriyoutomo.umm@gmail.com, \\ dwi_priyo@umm.ac.id, ORCID ID :0000-0002-2741-6773
}

\begin{abstract}
The purpose of this study was to explore and describe the analogy process of students in solving problems based on sample questions in terms of students' different thinking abilities. This study uses a qualitative approach with a descriptive-exploratory method. The subjects of this study were 7th grade students of SMP Negeri 3 Malang, Indonesia. The results showed that the convergent process of the students' analogy was encoding, concluding, mapping, and then applying. Convergent students begin the analogy process by understanding and calculating the variables posed by the target question. Convergent students are able to clearly communicate the analogy process in solving target problems and use mathematical language to express mathematical ideas appropriately. Divergent students take the same steps as convergent students in coding, concluding, but the stages are stages and applications.
\end{abstract}

Keywords: Analogy Process, Problem Solving, Divergent Thinking

Received: 07.12.2020 Accepted: 20.01.2021 $\quad$ Published: 04.02.2021

\section{INTRODUCTION}

Minister of Education and Culture Regulation No. 22 of 2006 concerning the objectives of learning mathematics states that students use reasoning on patterns and properties, perform mathematical manipulations in making generalizations, compile evidence or explain mathematical ideas or statements. One of the principles and standards of mathematics in schools is that students have the power to reason inductively (NCTM, 2001).

Inductive reasoning begins with making certain observations and then drawing broader conclusions based on observations (Remigio et al., 2014). Inductive reasoning is a general thinking skill, which is associated with almost all higher-order cognitive skills and processes, such as general intelligence, problem solving, knowledge acquisition and application, and analogical reasoning (Molnár et al., 2013). The concept of inductive reasoning refers to cognitive activities that produce conclusions that classically fulfill two criteria: (a) the direction of inductive reasoning moves from observing a particular case to the formulation of more general rules and (b) the level of confidence inductive reasoning is a form of reasoning under uncertainty because involves the formation of hypotheses about rules (Molnár et al., 2013). Science teachers in the Philippines are looking for teaching methods, which can enable students to develop reasoning skills in science, one way of achieving this is through the use of analogy (Remigio et al., 2014).

The ability to analogy is not only used in the application of mathematics, but almost all sciences require analogy skills, such as in the fields of physics, language, building design techniques and so on. The ability to analogize something can be used as a guide in solving problems that have a similar structure. The ability of analogy can also be used by people at any time to gain knowledge, this is in accordance with the opinion of Loc \& Uyen (2014) which states that 'analogy as a learning mechanism is a crucial factor in knowledge acquisition at all ages'. The role of analogy in mathematics in particular is in forming perspectives and finding solutions to problems (Isoda \& Katagiri, 2012). The more often students practice using analogy in solving math problems, the students' analogy thinking skills in solving problems in everyday life will be formed. Analogy may play an important role in problem solving, decision making, creativity, explanation and communication (Lancor, 2014).

In learning to use problem-solving strategies, the teacher trains students with questions ranging from easy to difficult ones. In an effort to help students solve problems, the teacher provides examples of questions and their solutions at once. Such a problem is usually called an 'example problem'. The sample questions have a structure similar to the practice questions and provide various concepts and procedures needed by students in completing the practice questions. Because the sample questions have several 
concepts and procedures, the students' analogy skills will greatly help students in solving math problems. To help students solve problems, it is necessary to know how the analogous thinking process of students in solving math problems. Analogy is used in mathematics learning to solve problems by means of students applying known knowledge to solve unknown problems (English, 2004). This means that analogy is one way of solving mathematical problems. Cognitive abilities of creative people that are closely related to problem discovery and problem solving are divergent thinking (Müller \& Pietzner, 2020).

Divergent thinking and convergent thinking are not completely separate, but are closely integrated (Sun et al., 2020). Research has found that generating ideas through divergent thinking is more difficult than choosing ideas using convergent thinking (Antink-Meyer \& Lederman, 2015; Sun et al., 2020). Given the importance of divergent thinking in creativity, training in divergent thinking skills has received greater attention in creativity development (Ritter \& Mostert, 2017; An et al., 2016; Forthmann et al., 2016; Sun et al., 2020). In contrast to convergent thinking, where people follow a set path, divergent thinking is an important skill for creative people to think creatively (Müller \& Pietzner, 2020). Divergent thinking requires many different solutions to one existing problem (Forthmann et al., 2016). Convergent thinking refers to the process of arriving at a single answer, solution, or conclusion (Gallavan \& Kottler, 2012). Divergent thinking can be described as the process of regaining existing knowledge and associating and combining unrelated knowledge in new and meaningful ways (Sun et al.,2020).

One of the topics of learning mathematics in high school that is interesting to research is the system of two-variable linear equations. This topic is interesting because it is very contextual in students' daily activities. SPLDV is a social arithmetic material that starts to introduce the example of a quantity asked by a question with two variables at once. In this topic, students are introduced to mathematical modeling and procedural knowledge related to this problem. Previous research found that only the analogy group experienced an increase in the balance task, these findings support the use of analogy learning to improve balance in preschool children (Chatzopoulos et al., 2020). In addition, other findings show that teaching through analogical reasoning improves mathematics learning, because teaching mathematical concepts through analogical reasoning modifies misunderstandings and difficulties for students in math problems (Mofidi et al., 2012).

Some of the explanations above explained that research on the analogy process in solving flat shape problems is interesting to study. Therefore, the purpose of this study was to explore and describe the analogy process of seventh grade junior high school students in solving SPLDV questions based on sample questions in terms of students' divergent thinking abilities.

\section{THEORITICAL REVIEW}

\section{Solve the problem}

Solving a problem is a basic activity for humans (Hadi \& Radiatul, 2014). Therefore to solve problems, people must learn how to solve the problems they face. Meanwhile, NCTM (2001) states that learning to solve problems is the main reason for learning mathematics. In solving mathematical problems students are required to be able to understand the mathematical concepts that are learned and be able to apply them in solving problems (Nasution, 2018).

Problem solving is one of the foundations of teaching mathematics (Tarim \& Öktem, 2016). Problem solving is a process that starts with initial contact with the problem and ends when an answer is received based on the information provided (Olaniyan et al., 2015). In addition, problem solving according to Hadi \& Radiatul (2014) is a basic ability that must be mastered by students.

Based on the explanation above, problem solving is a planned process that needs to be done to find answers to a problem by using concepts and ideas that must be mastered by students.

In solving the problem there are several stages. The problem solving stage used in this research is the problem solving stage according to Polya. According to Polya, the four stages are: a) understanding the problem, b) planning a strategy, c) implementing the plan and d) checking again (Hensberry \& Jacobbe, 2012; Tong \& Loc, 2017; Abdullah et al., 2015). According to Polya, the problem solving stage was chosen because the stages of problem solving proposed by G Polya were simple, the activities at each stage were clear, and allowed students to gain experience using their knowledge and skills to solve problems.

Suleiman (Olaniyan et al., 2015) found that problem solving according to Polya was preferred over the problem solving models of Gick and Bransford and Stein.

\section{Analogy Process in Solving Problems}

Analogy is a powerful cognitive mechanism used to learn new abstractions by students and is often used in the form of text, images, videos and verbal examples in traditional classrooms (Remigio et al., 2014). 
Wilbers and Duit (Lancor, 2014) argue that learning by analogy is not only about transferring structural features between source and target domains, but also the process of building relationships. Meanwhile, according to Mariah (Remigio et al., 2014) defines analogy as a concrete representation of the suitability between basic concepts and targets. Analogy as a comparison of something unfamiliar with something familiar to explain shared principles, such as a bridge between what you want to learn and what students already know (Lancor, 2014). From the description above, analogy is a sequence of steps to draw conclusions starting from comparing two things or two symptoms then looking for similarities in aspects, properties and structures between things that are not yet known and things that are already known first.

Analogy learning can limit the amount of verbal information that beginners access in the early stages of learning, leading to less reliance on declarative information and motor planning (Duijn et al., 2020). Based on the research results of Chui and Lin (Remigio et al., 2014) using analogy not only advances in-depth understanding of complex science concepts, but also helps students correct their misconceptions about concepts. Analogy has proven to be a useful tool in expressing students' thoughts and helping them understand new situations (Lancor, 2014).

In using analogy skills, students must be familiar with the concept of targets and be able to review the concept of analogy (Loc \& Uyen, 2014). Wong (Lancor, 2014) argues that constructing analogies serves to (a) make new situations familiar, (b) represent problems specifically from an individual's previous knowledge, and (c) stimulate abstract thinking about the underlying structures or patterns. In the problems of analogy reasoning, there are two questions, namely the source question and the target problem. The source problem has the characteristics: a) given before the target problem; b) in the form of easy and medium problems; c) can help solve the target problem or as initial knowledge in the target problem (English, 2004). The target problem is characterized by: a) a modified or extended source problem; b) the target problem structure is related to the source problem structure; c) is a complex problem (English, 2004).

The use of known problems is as information in terms of linking and comparing them with unknown problems so that the structure of the source problem can be applied to the target problem. This means that known problems can help solve unknown problems. In this case the known problem is the source problem and the unknown problem is the target problem. The source problem is the problem given before the target problem. The source problem can be used as initial knowledge in solving the target problem. The relationship between these characteristics in carrying out the analogy is that when obtaining a source problem, students then look at and solve the problem uses a concept that he already knows. Furthermore, in solving the target problem students identify the relevant properties of the source problem as initial knowledge to solve the target problem, then map the related traits. The following is an illustration of the analogy presented (English, 2004).

Source

Target

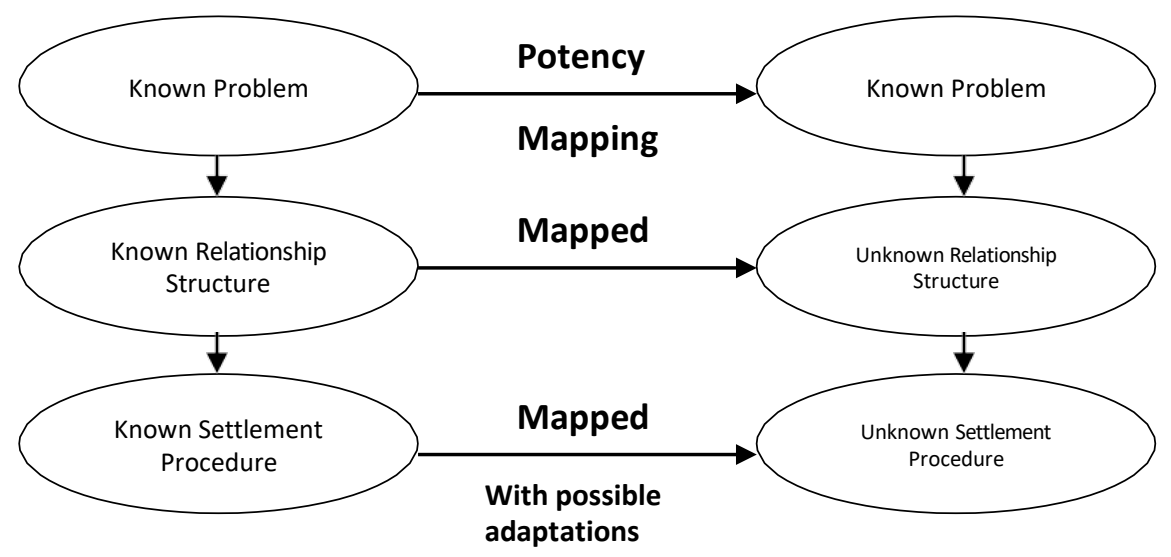

Figure 1. Analogical thinking process in solving Mathematics problems

Figure 1 explains that the analogy thinking process in solving mathematical problems is: 1) identifying the information contained in the source problem and the target problem; 2) mapping the structure of the relationship between the source problem and the target problem; and 3) map the structure of the source problem solving to the target problem. The process of reasoning using analogy includes encoding, inferring, mapping, and applying (English, 2004). 
Table 1. Stages of Analogy in Solving Problems (English, 2004).

\begin{tabular}{|l|l|}
\hline Analogy Stages & Stages of Problem Solving \\
\hline $\begin{array}{l}\text { Encoding (Encoding) } \\
\text { Students can understand the information contained } \\
\text { in the source problem and the target problem. }\end{array}$ & Understand the problem \\
\hline $\begin{array}{l}\text { Inferring (Inference) } \\
\text { Students can determine the structure and find the } \\
\text { source problem solving relational information }\end{array}$ & Searching for information \\
\hline $\begin{array}{l}\text { Mapping (Mapping) } \\
\text { Students can map relational structures / make plans } \\
\text { for solving source problems to target problems. }\end{array}$ & Make a plan \\
\hline $\begin{array}{l}\text { Applying (Application) } \\
\text { Students can apply the relational way of solving } \\
\text { source problems in solving the target problem }\end{array}$ & Carry out the plan \\
\hline
\end{tabular}

The role of analogy specifically in mathematics is to form perspectives and find solutions to problems (Isoda, M. \& Katagiri, 2012). This means that analogy is one of the tools used in solving mathematical problems, the more often students practice using analogy in solving mathematical problems, the analogical thinking process of students in solving problems outside of mathematics or in everyday life will be formed so that it will benefit life and the development of science. other knowledge. Mathematical analogy indicators for source questions and target questions according to English (2004) can be seen in table 2 .

Table 2. Analogy Indicators

\begin{tabular}{|l|l|}
\hline Analogy Stages & indicator \\
\hline Encoding & $\begin{array}{l}\text { Students know what information is known and what is being asked about } \\
\text { the target. }\end{array}$ \\
\hline Inferring & $\begin{array}{l}\text { Students are able to identify information related to source questions and } \\
\text { target questions. }\end{array}$ \\
\hline Mapping & $\begin{array}{l}\text { Shiva is able to map or plan the completion of the target problem based } \\
\text { on the solution to the source problem. }\end{array}$ \\
\hline Applying & $\begin{array}{l}\text { Students are able to apply the source question solving method to the } \\
\text { target questions and solve the questions correctly. }\end{array}$ \\
\hline
\end{tabular}

\section{Divergent and Convergent Thinking}

Divergent thinking is defined as thinking that generates several ideas, solutions or products, while convergent thinking leads to one correct answer as in the case of traditional ability tests (Sanchez-ruiz et al., 2015; Colzato et al., 2017). In particular, creativity has been conceptualized as divergent thinking or the performance of creative experts (An et al., 2016). Divergent thinking is chosen to represent a thinking style that allows many new ideas to be generated and more than one correct solution to a problem (Colzato et al., 2017). Divergent thinking is generally used to verify creative potential and capture the extent to which individuals create novelty (Kleibeuker et al., 2013). Whereas convergent thinking refers to analytical and evaluative thinking, and thinking quickly and focusing on the one best solution to a problem (Gabora, 2010). Unlike divergent thinking where each student can provide a reasonable but unique answer, students in convergent thinking are expected to respond with the same answer given to the teacher with little or no peer-to-peer interaction (Gallavan \& Kottler, 2012).

In learning practice in schools it is important to distinguish between activities related to divergent abilities and activities related to convergent thinking skills. Divergent thinking is easy to contrast with convergent thinking. Convergent thinking leads to conventional and correct ideas and solutions, while divergent thinking leads to original ideas and solutions (Runco \& Acar, 2012). In learning practice, convergent thinking is emphasized more than divergent thinking, where students often face multiple choice tests to find the right answer among several alternative answers compared to essay tests that allow many ways of solving (Colzato et al., 2017).

The tendency for divergence or convergence of students' thinking can be measured using standardized tests. Divergent thinking tests have dominated the field of assessment of creativity for decades (Runco \& Acar, 2012; Sanchez-ruiz et al., 2015). The Torrance test is basically a divergent thinking test based on the Guilford model, and has been very widely used as a creativity test (Baer, 2011). Guilford (Gallavan \& Kottler, 2012) identifies the characteristics of divergent thinking that strengthen 
learning, namely ideational fluency, associational fluency, expressional fluency, spontaneous flexibility, adaptive flexibility, elaboration, originality, and sensitivity to problems. The benefits of divergent thinking are concept attainment, vocabulary development, depth exploration, breadth expansion, context application, critical reasoning, conversational defense, classification labeling, example generation, and possibility advancement (Gallavan \& Kottler, 2012).

\section{METHODS}

This study uses a qualitative approach with descriptive-exploratory methods. Case study research design. This study reveals the analogous process of students in solving algebraic problems. Through a thorough and in-depth examination process, the researcher digs up student data about what is being thought, done, written and said when solving problems. The data are described as they are to obtain a natural picture of the analogy process of students in solving algebraic problems.

The subjects of this study were 6 grade 7 students of SMP Negeri 3 Malang, Indonesia. The determination of the research subject is based on the category of students' divergent thinking skills through the DT (Divergent Test) test. Two subjects were in the divergent thinking category and 2 subjects were Convergent Thinking. The respective subject codes are C1, C2, D1, and D2.

Data collection techniques in this study were tests and interviews. The test used is the analogy test which is conducted to determine the analogy process of the research subject. The test in question can be seen in table 3. Problem source is done by the teacher as an example to help students in doing practice questions. The questions for this exercise are called the target questions. The concepts and principles in the source problem are the same as in the target problem. The method and procedure for solving the source questions are intended by the teacher to be a guide for students to solve the target questions. Mathematical analogy indicators for source questions and target questions can be seen in table 2 . Interviews were conducted to confirm and complete data on student answers. This interview is unstructured because the questions asked depend on the students' written answers to the questions given.

The data analysis technique used was the interactive technique of Miles and Huberman (Sugiyono, 2011). The data analysis process starts with data reduction, continues with data presentation, and ends with drawing conclusions. Data reduction is the process of clarifying, classifying, removing unnecessary data, and classifying data obtained from the field. The data were described systematically according to the divergent thinking ability category group then analyzed based on the mathematical analogy indicator. The presentation of the analogy process data was compiled by the research subject, starting with the presentation of the student's written answer data followed by the results of interviews with the subject and then the results of the analysis of each analogy indicator. The drawing of research conclusions is supported by valid data, at this stage the conclusions presented by the researcher are based on all the results of data analysis obtained.

Table 3. Problem Source and Problem Target

\begin{tabular}{|c|c|}
\hline Example Problem / Problem Source & Practice Questions / Target Questions \\
\hline $\begin{array}{l}\text { Cahaya bought } 4 \text { notebooks and } 3 \text { pens, she paid } \\
\text { IDR } 19,500.00 \text {. If he buys } 2 \text { notebooks and } 4 \\
\text { pens, he will have to pay Rp. 16,000.00. } \\
\text { Determine the price of a notebook and a pen! }\end{array}$ & $\begin{array}{l}\text { Parlan and Surti work at a bag factory. Parlan can } \\
\text { complete } 3 \text { bags every hour and Surti can } \\
\text { complete } 4 \text { bags every hour. The number of } \\
\text { working hours for Parlan and Surti is } 16 \text { hours a } \\
\text { day with the number of bags made by both of } \\
\text { them is } 55 \text { bags. If their working hours are } \\
\text { different, determine their working hours } \\
\text { respectively! }\end{array}$ \\
\hline
\end{tabular}

\section{RESULT}

\section{Process analogy C1}

The subject can describe all the answers to the target questions by performing the analogy stage appropriately, this can be seen in the students' answers and the following interview results. 
Example: $\operatorname{Parlan}(\mathrm{X})$

Then : \begin{tabular}{rl|c}
$3 X+4 Y=55$ & $x 1$ & $3 X+4 Y=55$ \\
$X+Y=16$ & $x 3$ & $3 X+3 Y=48-$ \\
$Y$ & \\
$Y$ & \\
$X+Y=7$ & $=16$ \\
$X+7$ & $=16$ \\
$X$ & $=16-7$ \\
$X$ & $=9$
\end{tabular}

So, Parlan 9 and Surti 7

Figure 2. Answers to C1 target questions

From the answer in Figure 2, the subject starts the work by considering what is being asked by the questions, namely $\mathrm{x}$ and $\mathrm{y}$. Creating a mathematical model based on the information understood (system of linear equations). These two things show that the subject knows what is known and what is being asked (encoding). Subjects are able to plan problem solving by making a system model of linear equations, namely $3 \mathrm{x}+4 \mathrm{y}=55$ and $\mathrm{x}+\mathrm{y}=16$ (mapping). Furthermore, the subject solves a system of linear equations using the elimination and substitution method as the solution to the source problem. Subjects are able to correctly answer questions about the target (Applying). The following interview results will complement the information about the subject's analogy process in solving the target questions.

$\mathrm{P} \quad$ : "What do you get in common in doing this problem"?

C1 : "solving the two problems (source problem and target problem) using an example, making a system of linear equations, using elimination and substitution"

P : : "How do you solve the target problem?"

C1 : "It is the same as used in the source problem, at first I suppose the $\mathrm{x}$ and $\mathrm{y}$ hours for the time required by Parlan and Surti. Then make a system of equations based on the information from the problem. $3 x+4 y=55$ and $x+y=16$. Then I did the elimination and substitution until $x=9$ and $y=7$ were obtained.

P : "So how do you conclude your answer"?

C1 : "Parlan takes 9 hours and Surti 7 hours a day"

From the interview above, it appears that the subject understands the similarity of the concept, principle and method of settlement between the source question and the target question (inferring). The subject completes the target problem, the subject starts making $\mathrm{x}$ and $\mathrm{y}$ assumptions, makes a system of linear equations, completes systems of linear equations using the elimination and substitution method, then answers the questions on the target question. The way the subject solved the target problem was the same as that used in the source problem.

\section{Process analogy $\mathrm{C} 2$}

In the analogy process, the subject can describe all the answers to the target questions by doing the analogy stage correctly, this can be seen in the written answers and the following interview results.

Example: Parlan working hours $(X)$

Surti working hours $(\mathrm{Y})$

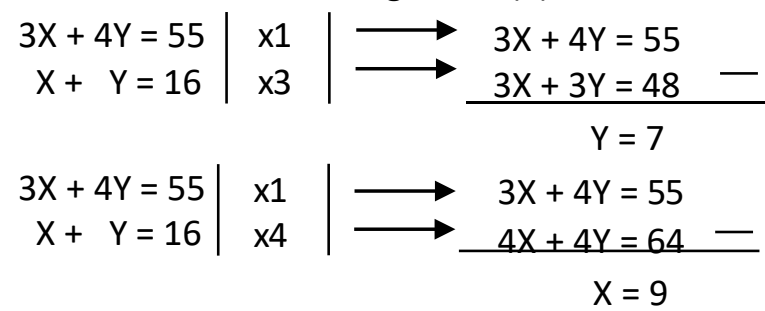

So, Parlan working 9 hours and Surti working 7 hours

Figure 3. Answers to C2 target questions 
From the answer in Figure 3, the subject starts the work by considering what is being asked by the questions, namely $\mathrm{x}$ and $\mathrm{y}$. Creating a mathematical model based on information that is understood. These two things show that the subject knows what is known and what is being asked (encoding). Subjects are able to plan problem solving by making a system model of linear equations (mapping). To complete information about the subject's analogy process in solving the target questions and the results of the interview.

$\mathrm{P}$ : "What are the same solutions to the source and target problems"?

C2 : "Solve the two problems using the equation, make a system of linear equations, use elimination"

$\mathrm{P}:$ "How did Ananda solve the target problem?"

C2 : "It is the same as that used in the source problem, at first I suppose it took Parlan and Surti to make bags with $\mathrm{x}$ and $\mathrm{y}$. Then make a mathematical model based on the information from the questions. $3 x+4 y=55$ and $x+y=16$. Then I did another elimination to get the value of $y$ and I did another elimination to get $x$.

$\mathrm{P}$ : "Why not use substitution to get the value for $\mathrm{x}$ ?

C2 : "It's the same as the result"

From the results of the interview above, the subject can identify and understand the similarity of concepts, principles and methods of solving between the source question and the target question (inferring). The solution process starts by calculating $\mathrm{x}$ and $\mathrm{y}$, making a mathematical model of a system of linear equations, then using the elimination procedure. The subject uses the same solution method as the source problem solution method. Getting the correct result is 9 hours needed by Parlan and 7 hours for Surti (Applying). If C1 uses the elimination method and then the substitution method, C2 uses only the elimination method to obtain the $\mathrm{x}$ and $\mathrm{y}$ values. The subject is solving the same target problem as that used in the source problem.

Table 4. Convergent Subject Analogy Process in Solving Problems

\begin{tabular}{|l|l|}
\hline Step & Subject activity \\
\hline Encoding & $\begin{array}{l}\text { Understand the information on the target question and understand } \\
\text { what the target question asks. }\end{array}$ \\
\hline Inferring & Find information related to source questions and target questions. \\
\hline Mapping & $\begin{array}{l}\text { Map / make plans for solving target questions based on solutions to } \\
\text { source questions. }\end{array}$ \\
\hline Applying & $\begin{array}{l}\text { Apply the source question solving method to the target problem and } \\
\text { solve the problem correctly. }\end{array}$ \\
\hline
\end{tabular}

\section{Process Analogy D1}

In the analogy process, the subject can describe all the answers to the target question by performing different analogy stages with subjects C1 and C2. Subject D1 uses a different solution method from the method of solving the source problem. This can be seen in the students' answers in Figure 4.

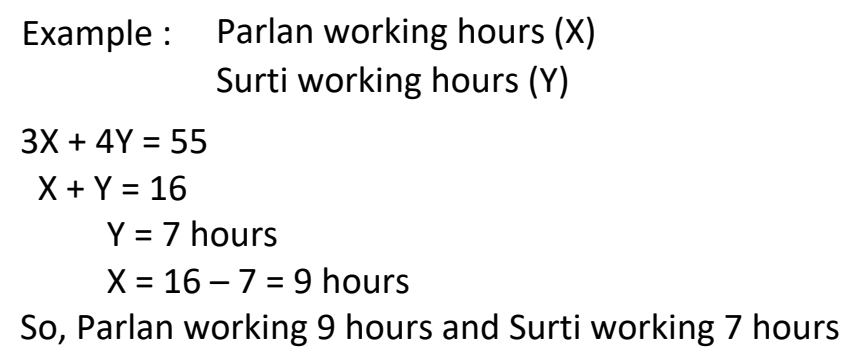

\section{Figure 4. Answers to Target Questions D1}

The subject understands the information and what is asked by the target questions. Subject takes the work hours required by Parlan and Surti with $\mathrm{x}$ and y (encoding). The subject is also able to make a solution plan, namely a system of linear equations (mapping). From the answer above, the question arises why $y=7$ suddenly appears and why the subject does not use the elimination method to solve the target problem as in the source problem solution. The following interview results provide answers to these questions. 
$\mathrm{P}$ : "why is there $\mathrm{y}=7$ on your answer sheet?

D1 : "yes ma'am. I created the equations $3 x+4 y=55$ and $x+y=16$, then I estimated that Parlan's time compared to Surti 4: 3. If the Surti time is 6 then the Parlan time is 8. Since the total time for Parlan and Surti is 16, then my estimate is the time for Surti 7 and then the Parlan time $\mathrm{x}=16-7$ $=9 "$

P : : is it fulfilled for the equation $3 x+4 y=55$ ?

D1 : meet ma'am. I checked earlier.

Q : Why not use the elimination method as the solution to the source problem?

D1 : I want another way ma'am.

$\mathrm{P} \quad$ : "Why isn't the guess-check method written on the answer sheet?

D2 : No, Mom. I'll just write down the results. I wrote the rest on opaque paper.

From the interview above, it is clear that the subject is able to identify similarities in concepts and principles between the target question and the source question. The subject also understands that the method of solving the source problem can be used to solve the target problem (inferring). Although D1 is able to perform the inferring process, D1 tries other methods. D1 uses the guess and check method or guess and check. Guess that the ratio of $x$ and $y$ is $4: 3$ because the first equation is $3 x+4 y=55$. Then guess that 8 is for the value of $\mathrm{x}$ and 6 is for $\mathrm{y}$. After checking, it turns out that 8 plus 6 does not equal 16 (second equation $\mathrm{x}+\mathrm{y}=16$ ). D1's next guess is 7 for $\mathrm{y}$ and 9 for $\mathrm{x}$. Then D1 plans to check whether $\mathrm{x}=9$ and $y=7$ satisfy the equations $x+y=16$ and $3 x+4 y=55$ (mapping). D1 does not write down part of the stages of solving the target problem, namely the process of guessing $y=7$ and checking the guess in the equation $3 x+4 y=55$ (inferring). The subject did not use the elimination method as used to solve the source problem, the subject used a different method, namely the guess-check method. Another thing that was revealed from the answer sheets and interview results was that part of the completion process was not written on the answer sheets. Subjects tend to write short answers.

\section{Process analogy D2}

D2 performs a different analogy process with the previous subject. D2 uses a different solution method but can decipher all the answers to the target question correctly, this can be seen in the answer to Figure 5 , below.

$$
\begin{aligned}
& \text { Parlan }=3 \text { bag } / \text { hours } \\
& \text { Surti }=4 \text { bag/hours } \\
& \text { Parlan }+ \text { Surti }=16 \text { hours }=55 \text { bag } \\
& \text { Parlan }=3,6,9,12,15,18,21,24,27=9 \text { hours } \\
& \text { Surti. }=4,8,12,16,20,24,28=7 \text { hours }
\end{aligned}
$$

Figure 5. Answers to questions on Target D2

Writing Parlan $=3$ bags $/$ hour, Surti $=4$ bags $/$ hour and Parlan + Surti $=16$ hours $=55$ bags shows that the subject understands the information in the question. By writing a series of numbers with up to 9 hours for Parlan and 7 hours for Surti, it shows that the subject also understands what the problem asks (encoding). See the series of numbers 3,6,9,... etc and 4,8,12, etc. It appears that D2 has a plan to solve the problem by writing multiples of 3 and multiples of 4 . The subject makes plans to solve different problems with solutions to the source problem. Why there is no example, linear equation system expression, elimination or substitution method to solve the target problem, the following interview results will explain all of that.

$\mathrm{P} \quad$ : "why is there no explanation?

D2 : "yes ma'am. I just wrote that Parlan produces 3 bags and Surti 4 bags in one hour.

P : : "why not make a linear equation model?

D2 : No ma'am, because I don't use the elimination method.

Q : Can Ananda use the solution as the source problem?

D2 : Yes, Mom. I've finished it on another paper.

$\mathrm{P}$ : "Try to explain how Ananda solved the problem!

D2 : The amount of time it took Parlan and Surti to make 55 bags is 16 hours. In the first hour Parlan produced 3 bags and Surti 4 bags, after two hours Parlan 6 bags and Surti 8 bags. And so on so that Parlan produced 27 bags and Surti 28 bags $(27+28=55)$. Parlan takes 9 hours and Surti 7 hours.

$\mathrm{P}$ : "Why not give an explanation on the answer sheet?

D2 : No, Mom. I write briefly. I wrote the rest on opaque paper 
Based on the results of the interview with D2, it appears that the subject is able to identify the similarity of concepts and principles between the target questions and the source questions. The subject also understands that the method of solving the source problem can be used to solve the target problem (inferring). Even though the subject was able to perform the inferring process, the subject tried other methods. D2 uses the make an Organized list method. The first row is how many bags Parlan generates every hour. The second row is the number of bags that Surti makes every hour. Both sequences will stop when the last term is 55. It occurs in the 9th term in the Parlan series and the 6th term in the Surti series. So it takes Parlan 9 hours and Surti 7 hours. The subject did not use the elimination method as used to solve the source problem, the subject used a different method, namely the method of registering in an organized manner. Another thing that was revealed from the answer sheets and interview results was that many completion processes were not written on the answer sheets. The subject's compulsion to produce short answers results in erroneous mathematical expressions. The first and second "=" signs express "the number of bags made by Parlan". The third "=" sign expresses "the time taken by Parlan and Surti" and so on.

Table 5. Convergent Subject Analogy Process in Solving Problems

\begin{tabular}{|l|l|}
\hline Step & Subject activity \\
\hline Encoding & $\begin{array}{l}\text { Understand the information on the target question and understand } \\
\text { what the target question asks }\end{array}$ \\
\hline Inferring & Identify information related to source questions and target questions. \\
\hline Mapping & $\begin{array}{l}\text { Make different plans to solve the target questions. Actually the subject } \\
\text { is able to make the same plan as the one in the source question. }\end{array}$ \\
\hline Applying & $\begin{array}{l}\text { Apply a different solution to the solution to the source problem. The } \\
\text { subject gets the correct answer to the target question question. }\end{array}$ \\
\hline
\end{tabular}

\section{DISCUSSION AND CONCLUSIONS}

Based on the results of the research data analysis that has been stated above, the analogy process of students in solving problems can be presented in the following chart.

Problem Source

ProcessAnalogy

Problem Target

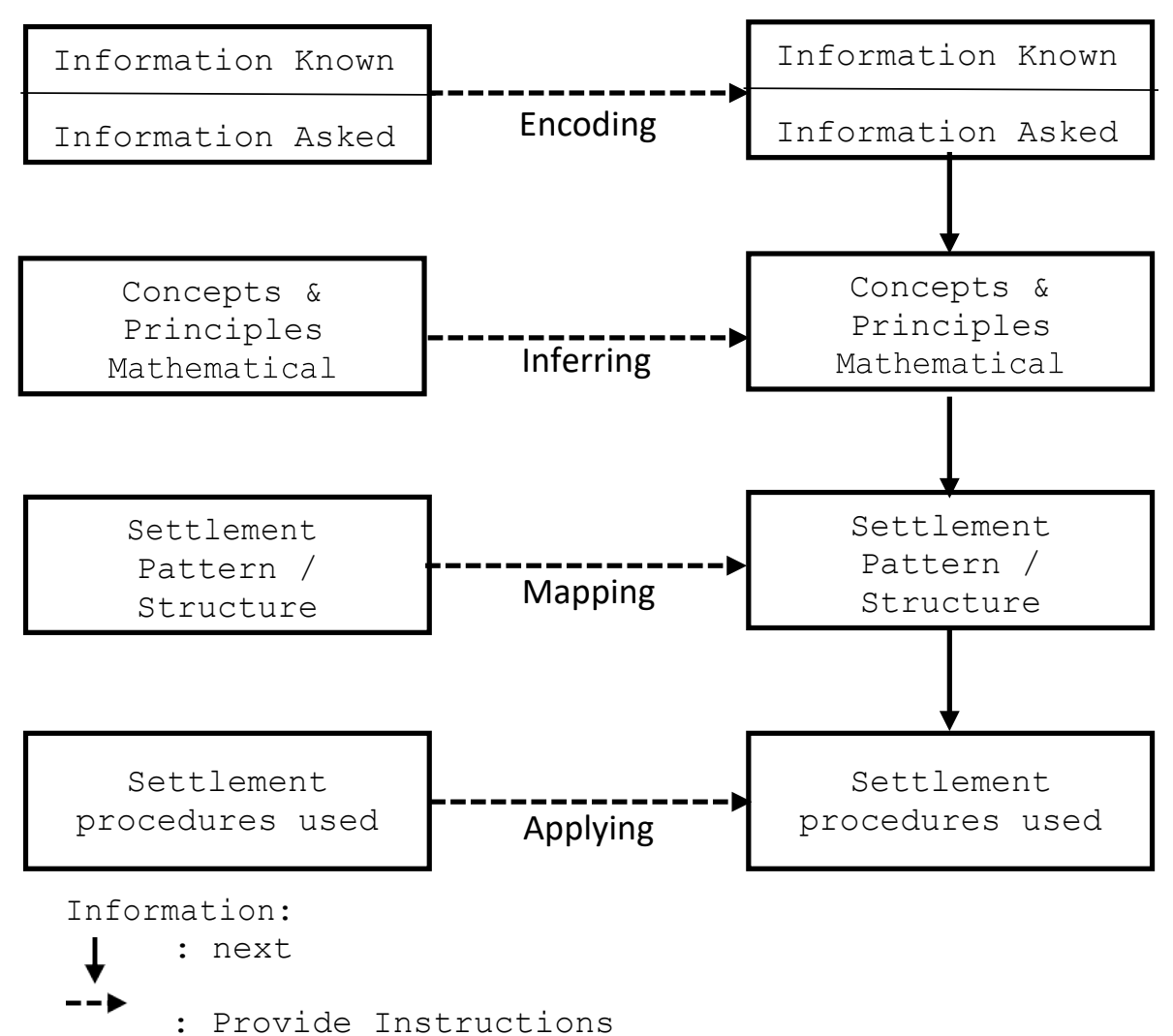


Figure 6. Analogical Thinking Process

\section{Convergent Student Analogy Process}

Convergent students carry out the analogy process, namely encoding, inferring, mapping, and then applying. The convergent student begins the process of analogy by supposing $\mathrm{x}$ and $\mathrm{y}$ for the variable asked by the problem. Understand the information from the target questions as material for making a completion plan. Both calculating and understanding the information about the questions are the encoding stages. Then the convergent students compare information from the source questions with the target questions. Things that are compared include concepts, principles, mathematical models, and method of solving problems (Inferring). This is in accordance with Remigio et al., (2014) who say analogy is a mapping of knowledge from the base to the target.

The next stage, the convergent students made a mathematical model in the form of a system of linear equations. The system of linear equations is made based on the information obtained from the problem using the $\mathrm{x}$ and $\mathrm{y}$ variables as for example in the encoding stage. The stage of making a linear equation system model using the $\mathrm{x}$ and $\mathrm{y}$ variables according to English (2004) is the mapping stage. At the Mapping stage students must be able to analyze and solve target questions with the correct method. Errors at the mapping stage will be followed at a later stage. In the applying stage, students carry out the plan, which is to solve the target problem using the method of elimination and substitution as in the solution to the source problem. This is in line with Gallavan \& Kottler (2012) which states that students in convergent thinking respond to answers in the same way as the questions given to the teacher. From the process of eliminating the system of equations, the $\mathrm{x}$ value is obtained. The $\mathrm{y}$ value is obtained from the substitution process. By obtaining the $\mathrm{x}$ and $\mathrm{y}$ values then the students answered the questions posed by the target questions. This is consistent with what Lancor (2014) studied by analogy not only about transferring structural features between source and target domains, but also the process of building relationships. Convergent students are able to clearly communicate the analogy process in solving the target problem.

\section{Divergent Student Analogy Process}

If the convergent student performs the encoding, inferring, mapping, and then applying analogy process, the divergent student performs different steps in the mapping and applying stages. At the encoding stage, divergent students begin the analogy process by considering $\mathrm{x}$ and $\mathrm{y}$ for the variables asked by the questions or detailing the relationship between time and the number of bags produced. This evidence shows that the subject understood the information and what the questions asked. Divergent students find information related to the source questions and the target questions. The inferring process passed by divergent students is still used to make plans for solving target questions. As has been explained by Sternberg (English, 2004) that inferring is a process of looking for relationships contained in the source problem to solve the target problem.

At the mapping stage, divergent students make different problem-solving plans with convergent student solution plans. After getting inspiration from the solution to the source problem, divergent students try to make a different solution plan from the solution to the source problem. This is in accordance with Colzato et al., (2017) that divergent thinking makes it possible to find many new ideas. The subject guesses the value of the variable in question then checks the correctness of the guess. This is consistent with Lancor (2014) that analogy has proven to be a useful tool in expressing students' thoughts and helping them understand new situations.

At the applying stage, students carry out the plan that was made at the mapping stage. The student guesses the value of $\mathrm{x}$ and $\mathrm{y}$ based on the information on the problem then checks the value of the guess in the system of equations. If the guess value satisfies the system of equations, then that value is used to answer the question questions. Likewise in the method of making an organized list, divergent students make a list of numbers with a certain pattern for the first variable and the second variable. The sequence of numbers stops at the nth term according to the information about the target. By obtaining the $\mathrm{x}$ and $\mathrm{y}$ values then the students answered the questions posed by the target questions. The use of analogies has been shown to be very effective in teaching students as it helps motivation and visualizes difficult concepts (Nworgu \& Otum, 2013).

Besides tending to use different methods, divergent students also tended to give short and short answers. The subject's encouragement to make short answers resulted in many verbal expressions that should have been not written on the answer sheet, so that the proposed solutions were less clear to the teacher. 


\section{CONCLUSION}

The process of converging student analogy is encoding, inferring, mapping, and then applying. Convergent students start the process of analogy by understanding and calculating the variables asked by the target question. The next stage is to understand the relationship between the source questions and the target questions. Then the students make plans for solving attractive problems by modeling a system of linear equations. In the applying stage, students carry out the plan, which is to solve the target problem using the method of elimination and substitution as in the solution to the source problem. Convergent students are able to clearly communicate the analogy process in solving the target problem and use mathematical language to express mathematical ideas appropriately.

Divergent students do the same steps as convergent students in the encoding, inferring, but different stages of mapping and applying. At the mapping stage, divergent students make a problemsolving plan that is different from the solution plan for the source problem. Students use the check-guess method and make an organized list. Furthermore, students carry out the plans that have been made at the mapping stage until they find the $\mathrm{x}$ and $\mathrm{y}$ values. By obtaining the $\mathrm{x}$ and $\mathrm{y}$ values then the students answered the questions posed by the target questions. At the applying stage, students carry out the plan by guessing and checking and making an organized list.

The tendency of divergent students to give short answers resulted in students making mistakes in expressing solution ideas and ignoring verbal expressions that should be written on the answer sheet.

\section{REFERENCES}

Abdullah, A. H., Abidin, N. L. Z., \& Ali, M. (2015). Analysis of Students' Errors In Solving Higher Order Thinking Skills (HOTS) Problems For The Topic Of Fraction. Asian Social Science, 11(21), 133-142.

An, D., Song, Y., \& Carr, M. (2016). A Comparison of Two Models of Creativity: Divergent Thinking And Creative Expert Performance. Personality and Individual Differences, 90, 78-84. https://doi.org/10.1016/j.paid.2015.10.040

Antink-Meyer, A., \& Lederman, N. G. (2015). Creative Cognition in Secondary Science: An Exploration of Divergent Thinking In Science Among Adolescents. International Journal of Science Education, 37(10), 1547-1563. https://doi.org/10.1080/09500693.2015.1043599

Baer, J. (2011). How Divergent Thinking Tests Mislead Us: Are the Torrance Tests Still Relevant in the 21 Century? The Division 10 Debate. Psychology of Aesthetics, Creativity, and the Arts, 5(4), 309-313. https://doi.org/10.1037/a0025210

Chatzopoulos, D., Foka, E., Doganis, G., Lykesas, G., \& Nikodelis, T. (2020). Effects of Analogy Learning On Locomotor Skills And Balance Of Preschool Children. Early Child Development and Care, 1-9. https://doi.org/10.1080/03004430.2020.1739029

Colzato, L. S., Szapora, A., Lippelt, D., \& Hommel, B. (2017). Prior Meditation Practice Modulates Performance and Strategy Use in Convergent- and Divergent-Thinking Problems. Mindfulness, 8(10), 10-16. https://doi.org/10.1007/s12671-014-0352-9

Duijn, T. van, Crocket, H., \& Masters, R. S. W. (2020). The Role Of Instruction Preference In Analogy Learning: Brain Activity and Motor Performance. Psychology of Sport \& Exercise, 47, 1-9. https://doi.org/10.1016/j.psychsport.2019.101615

English, L. D. (2004). Mathematical and Analogical Reasoning in Early Childhood. Lawrence Erlbaum Associates.

Forthmann, B., Gerwig, A., Holling, H., Çelik, P., Storme, M., \& Lubart, T. (2016). The be-Creative Effect In Divergent Thinking: The Interplay of Instruction And Object Frequency. Intelligence, 57, 25-32. https://doi.org/10.1016/j.intell.2016.03.005

Gabora, L. (2010). Revenge of the Neurds: Characterizing Creative Thought in terms of the Structure and Dynamics of Memory. Creativity Research Journal, 22(1), 1-13. https://doi.org/10.1080/10400410903579494

Gallavan, N. P., \& Kottler, E. (2012). Advancing Social Studies Learning for the 21st Century with Divergent Thinking. The Social Studies, 103(4), 165-170. https://doi.org/10.1080/00377996.2011.605641

Hadi \& Radiatul. (2014). Improved Resistivity and Surface Morphology of Laser Treated $\mathrm{Cr} / \mathrm{Pd}$ Metal Contact Sputter Deposited on Si. Journal of Science and Technology, Vol. 9(No. 3), 101-105.

Hensberry, K. K. R., \& Jacobbe, T. (2012). The Effects of Polya's Heuristic And Diary Writing On Children's Problem Solving. Math Ed Res J, 49, 59-85. https://doi.org/10.1007/s13394-012-0034-7

Isoda, M. Dan Katagiri, S. (2012). Mathematical Thinking. World Scientific.

Kleibeuker, S. W., Dreu, C. K. W. De, \& Crone, E. A. (2013). The Development of Creative Cognition Across Adolescence: Distinct Trajectories For Insight And Divergent Thinking. Developmental Science, 16(1), 2-12. https://doi.org/10.1111/j.1467-7687.2012.01176.x

Lancor, R. A. (2014). Using Student-Generated Analogies to Investigate Conceptions of Energy: A 
multidisciplinary study. International Journal of Science Education, 36(1), 1-23. https://doi.org/10.1080/09500693.2012.714512

Loc, N. P., \& Uyen, B. P. (2014). Using Analogy in Teaching Mathematics : An Investigation of Mathematics Education Students in School of Education - Can Tho University. International Journal of Education and Research, 2(7), 91-98.

Mofidi, S. A., Amiripour, P., \& Zadeh, M. H. B. (2012). Instruction of Mathematical Concepts Through Analogical Reasoning Skills. Indian Journal of Science and Technology, 5(6), 2916-2922.

Molnár, G., Greiff, S., \& Csapó, B. (2013). Inductive Reasoning, Domain Specific And Complex Problem Solving: Relations And Development. Thinking Skills and Creativity, 9, 35-45. https://doi.org/10.1016/j.tsc.2013.03.002

Müller, S., \& Pietzner, V. (2020). Comparative Study of Divergent Thinking among Participants in a German Science Competition and Pupils in a Control Group. Eurasia Journal of Mathematics, Science and Technology Education, 16(10), 1-16. https://doi.org/10.29333/ejmste/8408

Nasution, F. Y. (2018). Misconception's Analysis of Students Junior High School In Solving Algebra Problems Term Of Field Independent And Field Dependent Cognitive Styles. The Internasional Conference on Mathematical Analysis, 1-6.

NCTM. (2001). Perspectives on Principles and Standards for School Mathematics. School Science and Mathematics, 101(6), 277-279.

Nworgu, L. N., \& Otum, V. V. (2013). Effect of Guided Inquiry with Analogy Instructional Strategy on Students Acquisition of Science Process Skills. Journal of Education and Practice, 4(27), 35-41.

Olaniyan, Olatide, A., Omosewo, Esther, O., \& Levi, I. (2015). Effect of Polya Problem-Solving Model On Senior Secondary School Students' Performance In Current Electricity. European Journal of Science and Mathematics Education, 3(1), 97-104.

Remigio, K. B., Yangco, R. T., \& Espinosa, A. A. (2014). Analogy-Enhanced Instruction: Effects on Reasoning Skills in Science. Malaysian Online Journal of Educational Sciences, 2(2), 1-9.

Ritter, S. M., \& Mostert, N. (2017). Enhancement of Creative Thinking Skills Using a Cognitive-Based Creativity Training. Journal of Cognitive Enhancement, 1(3), 243-253. https://doi.org/10.1007/s41465-016-0002-3

Runco, M. A., \& Acar, S. (2012). Divergent Thinking as an Indicator of Creative Potential. Creativity Research Journal, 24(1), 1-10. https://doi.org/10.1146/annurev.psych.55.090902.141502

Sanchez-ruiz, M., Pérez-gonzález, J. C., Romo, M., \& Matthews, G. (2015). Divergent Thinking And Stress Dimensions. Thinking Skills and Creativity, 17, 102-116. https://doi.org/10.1016/j.tsc.2015.06.005

Sugiyono. (2011). Metode Penelitian Kuantitatif, Kualitatif dan R\&B. Alfabeta.

Sun, M., Wang, M., \& Wegerif, R. (2020). Effects of Divergent Thinking Training On Students' Scientific Creativity: The Impact of Individual Creative Potential And Domain Knowledge. Thinking Skills and Creativity, 37, 1-10. https://doi.org/10.1016/j.tsc.2020.100682.

Tarim, K., \& Öktem, S. P. (2016). Mathematical Word-Problems That Require Realistic Answer. Cukurova Üniversitesi Eğitim Fakültesi Dergisi, 43(2), 19-38. https://doi.org/10.14812/cufej.2014.011.

Tong, D. H., \& Loc, N. P. (2017). Students Errors In Solving Mathematical Word Problems And Their Ability In Identifying Errors In Wrong Solutions. European Journal of Education Studies, 3(6), 226-241. https://doi.org/10.5281/zenodo.581482. 